$\left.\begin{array}{c}\text { Sournals } \\ \text { ONTERNATIONAL JOURNAL OF } \\ \text { ORGANIZATIONAL LEADERSHIP }\end{array}\right) \begin{gathered}\text { INDUSTRIAL } \\ \text { MANAGEMENT } \\ \text { INSTITUTE }\end{gathered}$

\title{
An investigation into the relationship between the organizational intelligence and the performance of Melli and Mehr Eghtesad banks managers in Ardabil
}

\author{
Fatemeh Bagheri Toolarood $^{{ }^{*}}$, Shahram Mirzaei Daryani ${ }^{2}$ \\ ${ }^{1}$ Department of Management, Gorgan Branch, Islamic Azad University, Gorgan, Iran \\ ${ }^{2}$ Department of Management, Ardabil Branch, Islamic Azad University, Ardabil, Iran
}

\begin{abstract}
Keywords:

The present study aimed to investigate the relationship between the organizational intelligence and the performance of Melli and Mehr Eghtesad banks managers in Ardabil. In the present study cross-correlation method was used. The population consisted of all managers and assistants of Melli and Mehr Eghtesad banks in Ardabil which were about 132 people. The main tools of data collection were a standardized questionnaire that assigned for organization intelligence and a researcher-made questionnaire measured the relationship between two variables. To test the hypothesis, Kolmogorov-Smirnov test, Spearman's Correlation coefficient, and Mann-Whitney U Test Statistics were used. The findings revealed that there was a significant relationship between the organizational intelligence variables and the performance of banks managers and there was no significant difference between the organizational intelligence of Melli and Mehr Eghtesad banks managers.
\end{abstract}

(C)AIMI Journals

\section{Introduction}

Organizational intelligence is the ability and efficiency of an organization to generate knowledge and use it to strategically adapt to its environment and it refers to an organization's intellectual ability to solve organizational problems which focuses on integration of technical and human aspects (Simic, 2005). Organizational intelligence is the 
capacity of an organization to mobilize all the available intelligence to the organization and it refers to concentrating ability to achieve their missions (Albrecht, 2002).

McMaster (1996) defines organizational intelligence as the skill to collect information from outside the organization to create different market and technology scenarios, to understand the environmental signs, to shift customer desires and requests to product design outcomes. Organizational intelligence is a quantitative criterion for the efficiency of the organization in the dissemination of information, decision-making, and implementation. Intelligence quotient (IQ) of an organization like a person's IQ is measurable and intelligent organizations like increase their mental ability as well as their physical ability (Piri, 2006).

There are different definitions of performance and each of the experts pointed to certain aspects of it. Performance can be seen as behavior. Following this, Armstrong (1994) refers to performance as achieving to goals with determined quality and quantity. Kane (1996) argues that performance is a process that a person does not care at all. Bernadin, Kane, Spina, and Johnson, (1995) believe that performance should be defined as operating results since these results establish a strong relationship with the organization's strategic objectives, customer satisfaction, and economic cooperation. Brumbach (1988) offers a more comprehensive view of performance involving behavior and results. He claims that performance means both behaviors and results. Following this, behavior emanates from the performer and transforms performance from the thought into action. Behaviors are not only tools to achieve results, but they are the consequences which are derived from physical and mental activities and can be considered apart from the results (Haghighi, Ahmadi, \& Raminmehr, 2009).

Success factors of organizations vary from the perspectives of experts but the impact of the performance of managers is a consensus among experts. According to sources of power and authority of managers, actions and their activities with an impact on the favorable or unfavorable process of organization has leading role.

(Rezaeian, 2013) considers the success factors of organization to be derived from the perspective and performance of managers. In order to this, the function itself is influenced by multiple factors and it seems that intelligence could be one of these factors. In the present study, seven variables of organizational intelligence from the perspective of Albrecht (2002) including strategic vision, shared fate, appetite for change, heart, alignment congruence, knowledge deployment, and performance pressure. To this end, the present study aimed to 
investigate the relationship between the organizational intelligence and performance of the Melli and Mehr Eghtesad banks managers of Ardabil.

\section{The Literature Review}

Nowadays, intelligence is prerequisite to many managerial implications and this reflects the changes of organizational insights and organizational thinkers about the issue of intelligence. Intelligence attracted much attention in many fields and one area which has shown a great interest for intelligence refers to management and organization. However, the concept for the organization and management team is in doubt and one of the reasons tends to be the lack of strong and coherent theoretical framework in this area. In addition, despite the passage of more than a decade of introducing the concept of intelligence, very little research has been done in this area.

Howson (2008) referred to organizational intelligence as a dynamic window to the outside environment which improves organizational performance and has focus on identifying and creating unknown environmental opportunities. Organizational intelligence means the ability and competence of an organization to generate knowledge and to use it strategically for adapting to environment and business place (Halal, 2006). To this end, the importance of performance is because of its role in the improvement of the organization workplace health.

Matsuda in 1992 with a study on the relationship between business intelligence and knowledge management executives concluded that success in business management and application and optimization of knowledge management process which leads to their performance improvement had a significant relationship with their organizational intelligence. Higher organizational intelligence causes the success of managers in knowledge management and changes the organization to a learning organization.

Albrecht (2003) in a research titled as the organizational intelligence survey preliminary assessment which was conducted among Australian managers collected the Australian managers’ opinions about the collective intelligence. In this study, 200 managers and senior managers participated in two meetings in two cities. Finally, Albrecht stated that Australian managers with an awareness of their organizational intelligence could gain a better understanding of their organization. Besides, the managers of the organizations would be able to have a new look toward the organization.

J. Chen, S. Chen, and Hung (2006) aimed to investigate the relationship between the organization communication, job stress, organizational commitment, and job performance of 
accounting professionals in Taiwan and America. The results showed that there was a little difference between the professional staff in terms of the organizational relationship and job stress in the United States and Taiwan. Besides, in terms of commitment and performance there was a significant difference among employees of the two countries which may be due to the cultural differences. The strengths of these companies in both countries were the employees' use of processes and effective communication channels that led to the commitment and organizational performance.

\section{Definition of Intelligence}

There is no consensus among psychologists with respect to the intelligence definition. Today, psychologists believe that intelligence is a set of capabilities by which one understands a concept and thinks and treats logically. However, there are elements of intelligence that most researchers agree and they have divided elements into three categories as follow:

The ability to engage in abstract affairs which states that intelligent people deal with abstract issues (ideas, symbols, and concepts) rather than with concrete issues (mechanical devices and sensory activities); the ability to solve problems refers the ability to deal with new situations not only giving already learned responses to familiar situations; and the ability to learn, in particular, the ability to learn abstractions including abstractions in words and other symbols as well as the ability to use them (Seif, 2004).

\section{The Concept of Organizational Intelligence}

Organizational intelligence is the mental ability of an organization that focuses on the integration of technical and human aspects to solve problems (Simic, 2005). Besides, it is the capacity of an organization to mobilize all its available intelligence capabilities and it refers to concentrating ability to achieve its missions (Albrecht, 2002). Also, McMaster (1996) defined organizational intelligence as the orientation capability, being reasonable, and acting according to the flexible, creative, and adoptive ways.

Some scientists have studied organizational intelligence from the perspective of epistemology. Cognitive approach, behavioral approach, and emotional and social approach are three categories of organizational intelligence. Due to this, the overall goal is to understand how the combination of different schools of thought can provide a comprehensive understanding of organizational intelligence in management and organizational development literature. 
Organizational intelligence is a social process that its underlying theories are based upon theories that have been ignored and the use of individual intelligence could not determine the social nature of organizational intelligence (Salehi Kordabadi, 2010). Matsuda (1992) referred to organizational intelligence as the overall mental abilities of an organization and it was determined as complex, interactive, cumulative and coordinating collections of human and machine intelligence of organization as a whole.

Halal (2006) stated that organizational intelligence is the capacity to create knowledge and it refers to its usage in terms of strategic to adopt to the market environment. Organizational intelligence is similar to IQ which is formed in an organizational level and is called organizational intelligence quotient (OIQ) and like IQ, it can be measured. Halal (2006) talks about organizational intelligence as a function of the five sub-cognitive systems, namely organizational structure, culture, the relations of beneficiaries, management of knowledge and strategic processes.

Cronquist (2004) defined organizational intelligence as a systematic processing of data from external sources to improve the ability to predict the future and cope with a changing environment. In addition, Jung (2009) argued that organizational intelligence is the ability of an organization to process more efficient and better exchange of practices, assessment, and reasoning in order to support efficient and effective decision-making in activities especially in planning, organizing, directing, leading and controlling the operations of the organization. Following these definitions, Albrecht (2002) referred to organizational intelligence as consisting of seven variables including strategic vision, shared fate, appetite for change, heart, alignment congruence, knowledge deployment, and performance pressure which are shown in Figure 1.

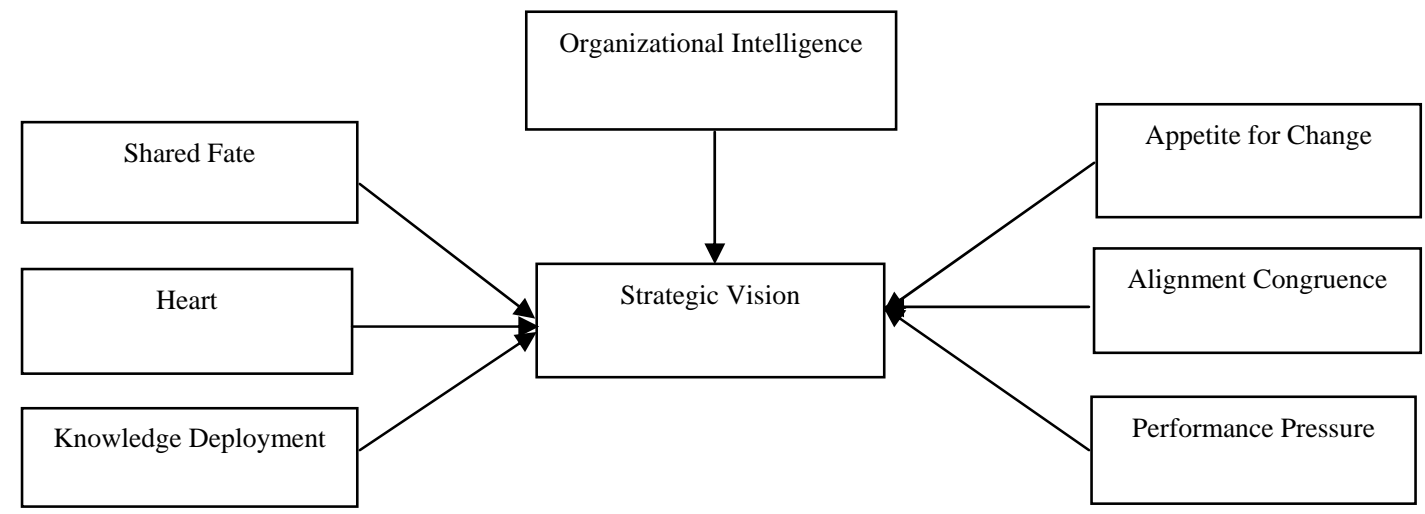

Figure 1. Index of organizational intelligence from the Albrecht's (2002) perspective 


\section{Performance}

There are different definitions of performance and each of the experts pointed to certain aspects of it. Armstrong (1994) refers to performance as achieving to goals with determined quality and quantity. Kane (1996) believes that performance is something that the person leaves behind and that exist apart from the goal. Bernadin et al. (1995) argues that performance should be defined as operating outcome since these outcomes build a strong relationship with the organization's strategic objectives, customer satisfaction, and economic cooperation. Brumbach (1988) offers a more comprehensive view of performance involving behavior and results.

\section{Performance Management}

Performance management is a way to facilitate communication and understanding between employees and supervisors and it leads to the creation of more favorable working environment and commitment to quality of service (Kaplan \& Norton, 1992). All organizations to achieve competitive advantage should go through the same selection process and they should share needs in growth, development and improvement. The following 10step approach is a strategy for the use of performance management systems in organizations. These processes are more flexible and they should be selected and used considering the needs of the organizations (Medori \& Steeple, 2000). A ten step approach that can improve organizational performance include strategy determination, goal determination, identification and improvement of processes, performance management frameworks, performance indicators, monitoring and control, improvement, improvement of processes, people, and communications.

\section{Different Kinds of Performance from the Perspective of Organizational Performance}

Duty performance includes the behavior of employees that directly contribute to converting resources into goods and services. In other words, duty performance is a set of specific commitments that the employee must do for receiving salary or for continuation of their recruitment.

Fixed duty performance includes clear responses to the demands which are common in natural state or at least it is predictable. In this case, the employee tends to use planning methods or procedures that are slightly different from one location to another. 
Adaptive duty performance unlike the fixed duty performance involves responds to unusual or unpredictable requests. Put differently, duty performance refers to the duties and responsibilities which are recorded in employees' job specification and are directly related with the performance of assigned duties such as monitoring staff attendance. To this end, field evaluation of this dimension requires certain standards. Another dimension of performance is underlying performance and it includes behaviors that give continuity to the survival of enterprise and social networks and psychological atmosphere that surrounds technical tasks (Kwong, \& Cheung, 2003).

\section{Research Hypotheses}

The main hypotheses of the study are as follow:

$\mathbf{H}_{\mathbf{1}}$ : There is a significant relationship between the organizational intelligence and the performance of Melli banks managers.

$\mathbf{H}_{2}$ : There is a significant relationship between the organizational intelligence and the performance of Mehr Eghtesad banks managers.

$\mathbf{H}_{3}$ : There is a significant difference between the organizational intelligence of Melli and Mehr Eghtesad banks managers.

The sub-hypotheses are presented as follow:

$\mathbf{H}_{1}$ : There is a significant relationship between the strategic vision and the performance of managers.

$\mathbf{H}_{1 \mathbf{a}}$ : There is a significant relationship between the strategic vision and the performance of Melli banks managers in Ardabil.

$\mathbf{H}_{\mathbf{1 b}}$ : There is a significant relationship between the strategic vision and the performance of Mehr Eghtesad banks managers in Ardabil.

$\mathbf{H}_{2}$ : There is a significant relationship between the shared fate and the performance of managers.

$\mathbf{H}_{\mathbf{2 a}}$ : There is a significant relationship between the shared fate and the performance of Melli banks managers in Ardabil.

$\mathbf{H}_{\mathbf{2 b}}$ : There is a significant relationship between the shared fate and the performance of Mehr Eghtesad managers in Ardabil. 
$\mathbf{H}_{3}$ : There is a significant relationship between the appetite for change and the performance of banks managers.

$\mathbf{H}_{\mathbf{3 a}}$ : There is a significant relationship between the appetite for change and the performance of Melli banks managers in Ardabil.

$\mathbf{H}_{3 \mathbf{b}}$ : There is a significant relationship between the appetite for change and performance of Mehr Eghtesad mangers in Ardabil.

$\mathbf{H}_{4}$ : There is a significant relationship between the heart and the performance of managers.

$\mathrm{H}_{4 \mathbf{a}}$ : There is a significant relationship between the heart and the performance of Melli banks managers in Ardabil.

$\mathrm{H}_{\mathbf{4 b}}$ : There is a significant relationship between the heart and the performance of Mehr Eghtesad managers in Ardabil.

$\mathbf{H}_{5}$ : There is a significant relationship between the alignment and the performance of managers.

$\mathbf{H}_{5 \mathbf{a}}$ : There is a significant relationship between the alignment and the performance of Melli banks managers in Ardabil.

$\mathbf{H}_{5 \mathbf{b}}$ : There is a significant relationship between the alignment and the performance of Mehr Eghtesad managers in Ardabil.

$\mathbf{H}_{6}$ : There is a significant relationship between the knowledge deployment and the performance of managers.

$\mathbf{H}_{\mathbf{6} \mathbf{a}}$ : There is a significant relationship between the knowledge deployment and the performance of Melli banks managers in Ardabil.

$\mathbf{H}_{6 \mathbf{b}}$ : There is a significant relationship between the knowledge deployment and the performance of Mehr Eghtesad managers in Ardabil.

$\mathbf{H}_{7}$ : There is a significant relationship between the performance pressure and the performance of managers.

$\mathbf{H}_{7 \mathbf{a}}$ : There is a significant relationship between the performance pressure and the performance of Melli banks managers in Ardabil.

$\mathbf{H}_{7 \mathbf{b}}$ : There is a significant relationship between the performance pressure and the performance of Mehr Eghtesad managers in Ardabil. 


\section{Method}

The data of the study was collected in the form of field research. It was a descriptive correlational study. The statistical population of this research consisted of 132 managers and assistants (112 from Melli bank and 20 from Mehr Eghtesad). We did not use Cochran formula to determine the sample size because of our limited statistical population. To collect data, a researcher-made questionnaire for organizational performance including 18 statements and a standardized questionnaire (Albrecht, 2002) for organizational intelligence including 48 statements were employed. It enjoyed acceptable levels of validity and reliability. They measured respondents' frequency of actual use by means of a five point Likert scale ranging from strongly disagree (1 point) to strongly agree (5 points). Initially, demographic information of the statistical sample including education, age, marital status, their organizational position, and past working experience was presented in the questionnaire. Table 1 shows the distribution of respondents according to their demographics.

Table 1

Demographic Information of Respondents

\begin{tabular}{|c|c|c|c|c|c|}
\hline & Items & Name of Bank & Numbers & $\begin{array}{l}\text { Frequency } \\
\text { Percentage } \\
\end{array}$ & $\begin{array}{c}\text { Communicative } \\
\text { Percentage }\end{array}$ \\
\hline \multirow{9}{*}{ Education } & \multirow{2}{*}{ Bachelor and Lower } & Melli & 61 & \multirow{2}{*}{$60 \%$} & \multirow{2}{*}{$60 \%$} \\
\hline & & Mehr Eghtesad & 7 & & \\
\hline & \multirow{2}{*}{ Bachelor of Art } & Melli & 25 & \multirow{2}{*}{$29 \%$} & \multirow{2}{*}{$89 \%$} \\
\hline & & Mehr Eghtesad & 8 & & \\
\hline & \multirow{2}{*}{ Philosophical Doctrine } & Melli & 3 & \multirow{2}{*}{$2 \%$} & \multirow{2}{*}{$91 \%$} \\
\hline & & Mehr Eghtesad & - & & \\
\hline & \multirow{2}{*}{ No Answer } & Melli & 9 & \multirow{2}{*}{$9 \%$} & \multirow{2}{*}{$100 \%$} \\
\hline & & Mehr Eghtesad & 1 & & \\
\hline & Total & & 114 & $100 \%$ & - \\
\hline \multirow{13}{*}{ Age } & \multirow{2}{*}{30 Years Old and Lower } & Melli & 1 & \multirow{2}{*}{$2 \%$} & \\
\hline & & Mehr Eghtesad & 1 & & \\
\hline & \multirow{2}{*}{$30-40$} & Melli & 38 & \multirow{2}{*}{$5 \%$} & \multirow{2}{*}{$5 \%$} \\
\hline & & Mehr Eghtesad & 8 & & \\
\hline & \multirow{2}{*}{$40-50$} & Melli & 41 & \multirow{2}{*}{$59 \%$} & \multirow{2}{*}{$64 \%$} \\
\hline & & Mehr Eghtesad & 5 & & \\
\hline & \multirow{2}{*}{50 and Higher } & Melli & 15 & \multirow{2}{*}{$39 \%$} & \multirow{2}{*}{$94 \%$} \\
\hline & & Mehr Eghtesad & 2 & & \\
\hline & \multirow{2}{*}{ No Answer } & Melli & 3 & \multirow{2}{*}{$6 \%$} & \multirow{2}{*}{$100 \%$} \\
\hline & & Mehr Eghtesad & - & & \\
\hline & Total & & 114 & $100 \%$ & - \\
\hline & \multirow{2}{*}{ Single } & Melli & 3 & \multirow{2}{*}{$90 \%$} & \multirow{2}{*}{$90 \%$} \\
\hline & & Mehr Eghtesad & - & & \\
\hline Marital Statues & Married & Melli & 88 & $3 \%$ & $93 \%$ \\
\hline
\end{tabular}




\begin{tabular}{|c|c|c|c|c|c|}
\hline & & Mehr Eghtesad & 15 & & \\
\hline & No A ncurr & Melli & 7 & 70 & 10004 \\
\hline & & Mehr Eghtesad & 1 & 170 & 10070 \\
\hline & Total & & 114 & $100 \%$ & \\
\hline & Monarar & Melli & 38 & & \\
\hline & IVIanaget & Mehr Eghtesad & 5 & $30 \%$ & $30 \%$ \\
\hline Organizational & A o & Melli & 52 & 20 & 000 \\
\hline Position & Mossistailt & Mehr Eghtesad & 9 & $5 \%$ & 5070 \\
\hline & No A ncuar & Melli & 8 & $7 \%$ & $100 \%$ \\
\hline & IN AnIs wer & Mehr Eghtesad & 2 & 170 & 10070 \\
\hline & Total & & 114 & $100 \%$ & \\
\hline & & Melli & 2 & & \\
\hline & Below 10 Y Yars & Mehr Eghtesad & - & $1 \%$ & $1 \%$ \\
\hline & 10- 50 Years & Melli & 19 & $22 \%$ & $23 \%$ \\
\hline & $10=-50$ redis & Mehr Eghtesad & 15 & $2<70$ & $20 \%$ \\
\hline Past Working & 15-20 Years & Melli & 57 & $51 \%$ & $74 \%$ \\
\hline Experience & & Mehr Eghtesad & 20 & & \\
\hline & 20 and More & Melli & 18 & $250 \%$ & $99 \%$ \\
\hline & 20 ard ivere & Mehr Eghtesad & 10 & 2070 & 5370 \\
\hline & No Ancurer & Melli & 2 & $1 \%$ & $100 \%$ \\
\hline & IVo AlIswer & Mehr Eghtesad & - & $1 \%$ & $100 \%$ \\
\hline & Total & & 114 & $100 \%$ & \\
\hline
\end{tabular}

The researcher-made questionnaire consisted of four sections which measured communications and interactions with colleagues, favorable business environment, financial performance, and bank rank promotion. While standardized questionnaire included of seven sections which examined strategic vision, shared fate, appetite for change, heart, alignment congruence, knowledge deployment, and performance pressure. In Table 2, the variables, number of questions for each variable, range of items, and their respective Cronbach's alphas are presented.

Table 2

The Variables, Number of Questions Assigned for each Variable, Range of Items, and Respective Cronbach's Alphas

\begin{tabular}{|c|c|c|c|c|c|}
\hline Questionnaires & Variables & $\begin{array}{l}\text { Number of } \\
\text { Items }\end{array}$ & Range of Items & $\begin{array}{l}\text { Cronbach's } \\
\text { Alpha }\end{array}$ & Total \\
\hline \multirow{8}{*}{ Organizational Intelligence } & Strategic Insight & 7 & $1-7$ & 0.81 & \multirow{8}{*}{0.84} \\
\hline & Common Destiny & 7 & 8-14 & 0.91 & \\
\hline & Willingness to Change & 7 & $15-21$ & 0.82 & \\
\hline & Courage & 7 & $22-28$ & 0.75 & \\
\hline & Agreement and Unity & 7 & 29-35 & 0.75 & \\
\hline & Application of Knowledge & 6 & $36-41$ & 0.76 & \\
\hline & Operating Pressure & 7 & $42-48$ & 0.87 & \\
\hline & Communications and Interactions with Colleagues & 5 & $1-5$ & 0.76 & \\
\hline
\end{tabular}




\section{Results}

The result of descriptive statistics summarizes in Table 3. Table 4 shows the results of the Kolmogorov Smirnov test (K-S) which indicated that the scores of each variable were not normally distributed (Asymp.Sig < 0.05). As a result, non- parametric tests were used for hypothesis testing.

Table 3

Descriptive Statistics of Research Variables

\begin{tabular}{ccccccccc}
\hline Variables & Numbers & Missing Data & Mean & $\begin{array}{c}\text { Standard Error } \\
\text { of Mean }\end{array}$ & Median & Mode & SD & Total \\
\hline $\begin{array}{c}\text { Organizational Intelligence } \\
\text { of Melli Bank }\end{array}$ & 97 & 1 & 3.63 & 0.06 & 3.60 & 3.56 & 59638. & 353.03 \\
$\begin{array}{c}\text { Organizational Intelligence } \\
\text { of Mehr Eghtesad }\end{array}$ & 15 & 1 & 3.91 & 0.14 & 3.91 & 3.42 & 56872. & 58.67 \\
$\begin{array}{c}\text { Performance of Melli Bank } \\
\quad \text { Managers }\end{array}$ & 97 & 1 & 3.55 & 0.07 & 3.58 & 4.08 & 76369. & 344.75 \\
$\begin{array}{c}\text { Performance of Mehr } \\
\text { Eghtesad Managers }\end{array}$ & 16 & 0 & 3.55 & 0.21 & 4.04 & 4.25 & 86435. & 56.83 \\
\hline
\end{tabular}

Table 4

One-Sample Kolmogorov-Smirnov Test

\begin{tabular}{lc}
\hline Variables & Asymp.Sig. (2-tailed) \\
\hline Organizational Intelligence & 0.000 \\
Organizational Performance & 0.006 \\
\hline
\end{tabular}

$* p>0.05$

Spearman's correlation coefficient was used for identifying the relationship between variables and investigating the possibility of each hypothesis except the third main hypothesis. Table 5 illustrates the results of Spearman's correlation coefficients. Preliminary analyses were performed to ensure no violation of the assumptions of normality, linearity, and homoscedasticity. There were strong positive correlations between the two variables in all hypotheses except the third one because spearman's correlation coefficient $(r)$ ranging from 0.50 to 1.0 reveals a strong positive linear relationship between variables $(p<0.001, \mathrm{n}=132)$.

Table 5

Hypotheses Testing

\begin{tabular}{cccc}
\hline Hypotheses & Banks & Correlation & Results \\
\hline Main Hypotheses & & & Confirmed \\
1 & Melli & $r=0.66$ & Confirmed
\end{tabular}




\begin{tabular}{|c|c|c|c|}
\hline \multicolumn{4}{|c|}{ Sub-hypotheses } \\
\hline \multirow{2}{*}{1} & Melli & $r=0.65$ & Confirmed \\
\hline & Mehr Eghtesad & $r=0.75$ & Confirmed \\
\hline \multirow{2}{*}{2} & Melli & $r=0.75$ & Confirmed \\
\hline & Mehr Eghtesad & $r=0.58$ & Confirmed \\
\hline \multirow{2}{*}{3} & Melli & $\mathrm{r}=0.45$ & Confirmed \\
\hline & Mehr Eghtesad & $r=0.02$ & Confirmed \\
\hline \multirow{2}{*}{4} & Melli & $r=0.38$ & Confirmed \\
\hline & Mehr Eghtesad & $r=0.56$ & Confirmed \\
\hline \multirow{2}{*}{5} & Melli & $\mathrm{r}=0.37$ & Confirmed \\
\hline & Mehr Eghtesad & $r=0.69$ & Confirmed \\
\hline \multirow{2}{*}{6} & Melli & $r=0.50$ & Confirmed \\
\hline & Mehr Eghtesad & $r=0.70$ & Confirmed \\
\hline \multirow{2}{*}{7} & Melli & $r=0.59$ & Confirmed \\
\hline & Mehr Eghtesad & $r=0.85$ & Confirmed \\
\hline
\end{tabular}

*Correlation is significant at the 0.01 level (2-tailed).

For testing the third main hypothesis which stated that there was a significant difference between the organizational intelligence of Melli and Mehr Eghtesad managers and comparing two population means, we used Mann-Whitney U test. Table 6 represents Mann-Whitney U test statistics.

Table 6

Mann-Whitney U Test Statistics

\begin{tabular}{lc}
\hline & Organizational Intelligence \\
\hline Mann-Whitney $U$ & 572.500 \\
Wilcoxon $W$ & 5325.500 \\
$Z$ & -1.32 \\
Asymp.Sig. (2-tailed) & 0.18 \\
\hline
\end{tabular}

According to the $\mathrm{Z}$ value was -1.32 with a significance level $(p)$ of $p=0.18$. The probability value $(p)$ was not less than or equal to 0.05 , so the result was not significant; therefore, there was no statistically significant difference in organizational intelligence of Melli and Mehr Eghtesad banks managers' performance and the third hypothesis was rejected.

\section{Discussion and Conclusion}

The present study aimed at investigating the relationship between the organizational intelligence and performance of Melli and Mehr Eghtesad banks' managers. The major finding of this study was that there was a strong significant relationship between the organizational intelligence variables and the managers’ performance. This finding confirmed 
the results of previous study conducted by Beikzadeh, Alaei, and Eskandari (2010) who stated that there was a significant relationship between the organizational intelligence and the performance of managers. However, the findings of the present study were not congruent with Gholami, Ghafuraian, and Ma’navipur (2011) and Keyvanara, Yazdkhasti, Bahrami, \& Masudian (2011) who mentioned that there were not any relationship between organizational intelligence and the performance of managers of universities in Garmsar and Isfahan due to the ignorance of the organizational intelligence variables and social, cultural, and informational obstacles in university environments. The findings of this study provided evidence in favor of previous studies such as Beikzadeh et al. (2010), Kashef and Khodadadi (2009), and Mokhtaripur and Kazemi (2010) who stated that there was a relationship between strategic vision, knowledge management, managers performance, and behavioral intelligence. In fact, managers who have a clear strategic vision choose the best path for reaching to their future destination regarding to this vision and regularly modify their management strategies with the time changes. It is obvious that the performance variables will be improved. In contrast to the above mentioned studies, the results of previous studies Bagherzadeh and Akbari dibaavar (2010), Noruzi (2010), and Salasel, Kamkar, and Golparvar (2009) revealed that strategic vision did not achieve to its desired position. In these three studies, the managers did not pose stable performance management; therefore, they easily replaced by another person. As a result, they did not feel a sense of belonging towards their organization and they could not deliver what they promised and present a strategic organization perspective of organization's future. Although the strategic vision has a direct positive relationship with the managers' performance and improve the quality of educational managers' performance, we cannot easily teach it. Management experts believe that the foundation of strategic vision consists of strong theoretical knowledge, high level of practical experience, and having systematic thinking. Therefore, banking authorities should select those managers who possess three features of abstract thinking, deductive thinking, and analytical thinking; otherwise, performance indicators of bank managers may remarkably reduce. Previous research such as Bakhshian (2012), Jamalzadeh and Gholami (2009), Kashef and Khodadadi (2009), Mokhtaripur and Kazemi (2010) referred to the positive significant correlation between the belief to the shared fate, the performance of the managers, organizational learning, behavioral intelligence, and entrepreneurship which was in line with the findings of this study. The managers actually feel a great sense of belonging towards their organizations and consider their organizations' future as their own future, and have empathy 
to their staff and other organization managers. All of these factors create and strengthen the relationship between the managers, subordinate managers, and superior executive managers; therefore, they can improve the key performance indicators of managers. The findings, however, run counter to the findings of Noruzi (2010) who mentioned that the students, administrative, and professors of Tehran University came from other parts of Iran with their own cultural values, customs, norms, and beliefs which prevent to build an atmosphere full of confidence, commitment, trust, sympathy, and friendship. These factors affected the current beliefs about shared fate and manifested them weakly in the society.

The studies of Bakhshian (2012), Khodadadi and Kashef (2010), and Zahraee and Rajaeepur (2011) referred to the positive significant relationship between the indicators of organizational health development, productivity management, and entrepreneurship and were in line with the findings of this study. Bakhshian (2012) and Zahraee and Rajaeepur (2011) achieved similar results for managing the knowledge-centered organizations. They stated that the groups more than dozen group members might face problems when there was not a set of operating rules. Gholami et al. (2011) confirmed among organizational intelligence variables, knowledge deployment had a direct impact on the performance of managers in the human resources sections of organizations. It means that the managers who believed in their own abilities to use knowledge deployment as one of organizational intelligence variables, showed the better performance in the human resource section. Generally speaking, the organizations which considered to knowledge deployment possess a set of suitable strategies for recruiting compatible and specialized forces. Jamalzadeh and Gholami (2009) stated that performance pressure had the lowest correlation with the organizational intelligence which indicated to the non-compliance of employees' organizational functions and their performance. Therefore, having ambiguous or non-defined organizational positions and carrying out organizational roles simultaneously caused to reducing the organizational learning curves.

\section{Suggestions for Further Research}

According to the results, there was a significant relationship between the organizational intelligence and its variables with performance of managers in Melli and Mehr Eghtesad banks in Ardabil. In order to strengthen the organizational intelligence of managers and to improve their performance in mentioned banks, some suggestions are presented. To strengthen the strategic vision of managers, the most important issue is providing each organization's mission. Banks must form teams for this aim and by examining the 
environment of banks they should identify opportunities and threats and take necessary measures in a timely manner.

Each year, the banks' senior managers should review and revise banks' strategy and inservice training courses must be held for managers to acquire more knowledge about the concept of strategic vision. In addition, the organizations should have regular schedule to identify and develop managers.

To strengthen the sense of shared fate among managers and employees, the managers should be willing to cooperate with employees in important issues and programs and share the outcome with them. In actual fact, all employees with more effort than usual would try to help managers to achieve the organizational goals. Besides, it is suggested that the managers create an environment among colleagues and managers with a feeling of confidence, trust, sympathy, and friendship and a sense of importance and merit. In such an environment, employees would try to fulfill their tasks willingly and would be proud of their job and its environment.

It is recommended that with studying the bank environment, bank activities should be continually growing and adapting to the changing environment; mechanisms should exist to support innovation in the bank such as product development teams and suggestion system; and a reward system should exist in banks for offering creative solutions and providing better banking processes.

For improving morale, it is suggested that managers through recreational programs, family holidays, and running proper programs in the national and religious festivals for employees along with their families enhance the quality of work in the bank. Also, it is recommended that managers in order to be able to create a model in the minds of the employees, they must do their job duties with passion and more desire. In this case, employees for achieving success and goals of organization will show extraordinary effort.

For strengthening unity and agreement, information systems should be designed in a way that to empower and align employees to perform their duties. Following this, to improve knowledge deployment, it is suggested to run virtual training and get use of financial sites. This consideration implies that setting up such courses make it possible for the people inside the bank to be aware of the latest changes and research on the relationship between the banks and their jobs. Also, managers should have a full understanding of diverse individual skills, qualifications, and competencies of employees in their branches to make the best use of it. 
To strengthen the performance pressure, personnel must be aware of their responsibilities and roles in the bank and the bank's expectations of employees' cooperation should be clearly described. Besides, there must exist a clear and continuous communication between managers and employees in banks. The results of the evaluation of employee performance must be given to employees as a feedback and fair payment system based on performance should be established.

In brief, it is imperative to state that concerning the developments and rapid changes occurring in organizations and consequently taking place in the organizational structures, the importance of human capital increases. Therefore, it is necessary to carry out a number of studies and research in this field. It is recommended to address pathology and barriers to the development of intelligence in banking centers in future research, to compare it with other similar cases in the country and the rest of the world as well, and by using intermediate variables to assess the effect of intelligence on the performance of managers of Melli and Mehr Eghtesad banks. In addition, it is suggested to use other methods and compare the results. Also, the present study was not free of limitation and they can be underlined briefly as follows: Not returning all questionnaires, lack of cooperation of organizations in the distribution and collection of questionnaires, lack of population in Mehr Eghtesad banks in Ardabil, and lack of research in financial organizations.

\section{References}

Albrecht, K. (2002). Organizational intelligence and Knowledge management the executive perspective. Retrieved, 2006, From. http://www.karl Albrecht.com.

Albrecht, K. (2003). Organizational intelligence survey preliminary assessment. provided by: Karl Albrecht international. Retrieved, 2006, From. http://www.karl Albrecht.com

Armstrong, M. (1994). Performance management: Key strategies and practical guidelines. Great Britain: Kogan Page Limited.

Bagherzadeh, M., \& Akbari dibaavar, A. R. (2010). The relationship between organizational intelligence and organizational agility in cultural heritage, tourism, and handicrafts in East Azarbaijan province. Paper presented at the First Conference on Organizational Intelligence and Business Intelligence, Tehran, Iran.

Bakhshian, A. (2012).Relationship between intelligence and entrepreneurship on Mazandaran university administrators (Unpublished master's thesis). Shahid RajaeeTeacher Training University, Tehran.

Bashiri, R. (2013). The effect of organizational intelligence of the heads of the branches on banking service quality of Maskan bank. Scientific \& Practical Journal of Maskan Bank, 2, 9-32.

Beikzadeh, J., Alaei, M. B., \& Eskandari, K. (2010). The relationship between organizational intelligence and manager's performance of government agencies in East Azarbayjan. Journal of Management Research, 3(8), 143-167.

Bernadin, H. K., Kane, J. S., Spina, J. D. R., \& Johnson, D. L. (1995). Performance appraisal design, development and implementation. In G. R. Ferris, S. D. Rosen, \& D. J. Barnum (Eds.), Handbook of human resource management (pp.). Cambridge, MA: Blackwell.

Brumbach, G. B. (1988). Some ideas, issues, and predictions about performance management. Public Personnel Management, 17(4), 387-402. 
Chen, J., Chen, S., \& Hung, J. Y. (2006). Organization communication, job stress, organizational commitment, and job performance of accounting professionals in Taiwan and America. Leadership \& Organization Development Journal, 27(4), 242-249.

Cronquist, B. (2004). Organizational intelligence: A dynamic knowledge creating activity embedded in organizational routines. Working Paper, Informatics research group, Kristiansted University, Sweden.

Ghafurian, H., Khanzadeh, G., \& Falamarzi, A. (2010). Efficacy of the management stability in manager’s performance. Quarterly Journal of Leadership \& Educational Management, 4(1), 67-82.

Gholami, S., Ghafuraian, H., \& Ma'navipur, D. (2011). The relationship between organizational intelligence and manager's performance. Quarterly Journal of Modern Industrial/Organizational Psychology, 2(6), 89-99.

Halal, W. E. (2006). Organizational intelligence. Melcrum Publishing Ltd.

Haghighi, M. A., Ahmadi, I., \& Raminmehr, H. (2009). The effect of organizational justice on employee performance. Organizational Culture Management, 7(20), 79-101.

Howson, C. (2008). Successful business intelligence: Secrets to making BI a killer App. New York: McGraw-Hill.

Jamalzadeh, M., Gholami, Y., Seif, M. H. (2009). A study of the relationship between organizational intelligence and organizational learning among staff and faculty board members of Islamic Azad University and presenting a pattern to upgrade organizational learning. Educational Management \& Leadership Quarterly, 2, 63-86.

Jung, Y. (2009). An approach to organizational intelligence management: A framework for analyzing organizational intelligence within the construction process (Unpublished doctoral dissertation). Faculty of the Virginia Polytechnic Institute and State University, U.S.

Kane, J. S. (1996). The conceptualization and representation of total performance effectiveness. Human Resource Management Review, Summer, 45-123.

Kaplan, R. S., \& Norton, D. P. (1992). The balanced scorecard: Measures that drive performance. Harvard Business Review, 69(1), 71-79.

Kashef, M., \& Khodadadi, M. R. (2009). The relationship between organizational intelligence and knowledge management in the departments of physical education in East and West Azarbaijan. Quarterly Journal of Research on Sciences Sport, 6(3), 179-192.

Keyvanara, M., Yazdkhasti, A., Bahrami, S., \& Masudian, Y. (2011). The relationship between knowledge management components and organizational intelligence in the faculties in Medical Sciences University of Isfahan. Journal of Health Information Management, 8(5), 673- 680.

Khodadadi, M. R., \& Kashef, M. (2010). The relationship between organizational intelligence and principals' productivity of physical education departments in East Azarbaijan. Journal of Sport Management, 4(4), 155-168.

Kwong, J., \& Cheung, M. (2003). Prediction of performance facets using specific personality trait in the Chinese context. Journal of Vocational Behavior, 6(4), 45-61.

Matsuda, T. (1992). Organizational intelligence: Its significance as a process and as a product. Proceedings of the International Conference on Economics, Management and Information Technology, Tokyo, Japan.

McMaster, M. D. (1996). The intelligence advantage: Organizing for complexity. Newton, MA: Butterworth-Heinemann.

Medori, D., \& Steeple, D. (2000). A framework for auditing and enhancing performance measurement system. International Journal of Operations \& Production Management, 20(5), 520-533.

Mokhtaripur, M., \& Kazemi, I. (2010). Comparison of organizational intelligence and moral intelligence of academic and non- academic principals' in public universities of Isfahan. Monthly Journal of Higher Education, 3(12), 31-51.

Noruzi, A. (2010). Assessment components of organizational intelligence in the faculty of engineering and humanities in University of Tehran. Paper presented at the First Conference on Organizational Intelligence \& Business Intelligence, Tehran, Iran.

Piri, Z. (2006). A model for organizational intelligence. Paper presented at the Fourth Annual Conference of Health Services Management Students across the Country, Tehran, Iran.

Rezaeian, A. (2013). Analysis and system design. Tehran: SAMT.

Salasel, M., Kamkar, M., \& Golparvar, M. (2010). The relationship between the organizational intelligence and organizational citizenship behaviors. Journal of Science \& Research in Applied Psychology, 40, 26-37.

Salehi Kordabadi, S. (2010). Organizational intelligence and sustainable development. Paper presented at the First National Conference of Organizational Intelligence and Business Intelligence, Tehran, Iran.

Seif, A. A. (2004). Educational psychology and the psychology of learning and teaching (8 ${ }^{\text {th }}$ ed.). Tehran: Agah Publication. 
Simic, I. (2005). Organizational learning as a component of organizational intelligence, information, and marketing aspect of the economically development of the Balkan Countries (Unpublished master's thesis). University of National and World Economy, Sofia, Bulgaria.

Zahraee, S. M., \& Rajaeepur, S. (2011). The relationship between organizational intelligence and organizational health in universities of Isfahan. Quarterly Journal of New Approaches in Educational Administration, Islamic Azad University, Marvdasht Branch, 2(2), 155-174. 